\title{
Enhancing the Enhanced Recovery Program in Colorectal Surgery - Use of Extended-Release Epidural Morphine $\left(\right.$ DepoDur $\left.{ }^{\circledR}\right)$
}

\author{
Rajeev Peravali, Rachael Brock, Elizabeth Bright ${ }^{1}$, Patricia Mills ${ }^{1}$, Dawn Petty ${ }^{2}$, Justin Alberts \\ Departments of Colorectal Surgery, ${ }^{1}$ Anaesthetics, and ${ }^{2}$ Pain Management Team, West Suffolk Hospital NHS Foundation Trust, Suffolk, UK
}

Purpose: DepoDur ${ }^{\circledR}$ is a single-dose extended-release morphine injection into the epidural space. It is not commonly used, but has many advantages over traditional analgesic regimens. We analyzed a number of these advantages in our case series in the context of the colorectal enhanced recovery program (ERP) and aimed to show that the ERP could be further enhanced by using DepoDur ${ }^{\circledR}$.

Methods: We conducted a prospective audit of all patients undergoing open and laparoscopic colorectal procedures where DepoDur $^{\circledR}$ was used between July 2010 and April 2012. Validated pain scores were used, and primary outcome measures were resting and dynamic pain, mobilization, and need for additional analgesia.

Results: Two hundred eighty patients were included in the case series. Good pain control was seen at 24 and 48 hours. Eighty-one percent of the patients required simple analgesia alone at 24 hours, and $62 \%$ required simple analgesia (paracetamol +/- nonsteroidal anti-inflammatory drugs) alone at 48 hours. Only a minority required additional oramorph and patient-controlled analgesia at 24 and 48 hours (19\% at 24 hours and $38 \%$ at 48 hours). Seventy-nine percent of the patients were mobilized at 24 hours, and $88 \%$ of the patients were mobilized at 48 hours.

Conclusion: DepoDur ${ }^{\circledR}$ is an effective alternative to conventional pain management techniques and may have a role in further enhancing the ERP.

\section{Keywords: Analgesia; Colorectal surgery; Pain management; Postoperative period}

\section{INTRODUCTION}

DepoDur $^{\circledR}$ (Pacira Pharmaceutical Inc., Parsippany, NJ, USA) is a single-dose extended-release formulation of morphine injected into the epidural space. It provides postoperative analgesia for up to 48 hours, and is the only licensed opiate for neuro-axial use in the United Kingdom (UK) [1]. DepoDur ${ }^{\circledR}$ is administered in a single dose of 7.5-10 $\mathrm{mg}$ as a single injection through a Tuohy needle

Received: September 2, 2013 - Accepted: March 1, 2014

Correspondence to: Rajeev Peravali, M.D.

Department of Colorectal Surgery, West Suffolk Hospital NHS Foundation

Trust, Hardwick Lane, Suffolk, UK

Tel: +441284713000, Fax: +441284701993

E-mail: rajeevperavali@doctors.org.uk

(C) 2014 The Korean Society of Coloproctology

This is an open-access article distributed under the terms of the Creative Commons Attribution NonCommercial License (http://creativecommons.org/licenses/by-nc/3.0) which permits unrestricted noncommercial use, distribution, and reproduction in any medium, provided the original work is properly cited. into the epidural space. The need for an epidural catheter is eliminated. The use of a liposomal drug delivery system results in slow, sustained release of the opiate. DepoDur ${ }^{\circledR}$ reaches full efficacy four hours after administration and in the interim, analgesia spinal bupivacaine or intravenous opiate analgesia may be also used [2].

The potential advantages of DepoDur ${ }^{\circledR}$ over conventional spinal and epidural techniques include improved pain scores [3-5], improved mobility [6], and lack of interference with thromboprophylaxis regimens [4]. Much of this evidence comes from orthopedic, obstetric and gynecological surgery where studies have shown effective long-lasting analgesia in the absence of large concentrations of opioids, as well as better patient activity levels and patient satisfaction $[4,7,8]$. Very little evidence exists in colorectal surgery. To further analyze these advantages, we conducted a prospective audit of all colorectal cases at our institution in which DepoDur $^{\mathbb{B}}$ was used. To our knowledge, this is the largest case series reporting the use of DepoDur ${ }^{\circledR}$ in colorectal surgery in the English literature. 


\section{METHODS}

Prospective data were collected on all patients undergoing colorectal surgery where DepoDur ${ }^{\circledR}$ was used between July 2010 and April 2012. Data were collected from the first patient that started receiving DepoDur ${ }^{\mathbb{R}}$ at our institution. Data were recorded intraoperatively by the anesthetic team and postoperatively by the specialist pain team by using a set proforma. Contraindications to conventional epidural anesthesia apply to DepoDur ${ }^{\circledR}$ injection, and when these were present, DepoDur ${ }^{\mathbb{B}}$ was not used. These contraindications include anatomical abnormalities, previous spinal surgery, coagulopathy, infection at the site of injection, septicaemia, and allergy. All patients received regular oral paracetamol and nonsteroidal anti-inflammatory drugs (NSAID), unless contraindicated.

The primary outcome measures were dynamic pain (pain on movement from a bed to a chair) and resting pain (pain when not moving), need for additional analgesia, and mobilization. Validated pain scores were used to record pain. Length of stay (defined as the number of days the patient remained in hospital after the operation) was also recorded. Data on side effects were also recorded. Data were managed using Microsoft Excel. Parametric variables were compared using the paired t-test, and significance was set at $\mathrm{P} \leq 0.05$.

\section{RESULTS}

The total number of cases included in this series was 280 . One hundred forty-five (52\%) were male and 135 (48\%) were female. The median age was 68.9 years (interquartile range [IQR], 19.6 years). The procedures carried out are shown in Table 1 . Table 2 further breaks down the noncategorized operations. One hundred twelve of the surgeries (40\%) were performed laparoscopically, and 3 surgeries (1\%) were converted from laparoscopic to open; for purposes of data analysis, these were regarded as open surgeries.

Table 1. Procedures carried out

\begin{tabular}{lc}
\hline Procedure group & No. of cases (\%) \\
\hline Right hemicolectomy & $82(29)$ \\
Left hemicolectomy & $42(15)$ \\
Total colectomy & $4(1)$ \\
Subtotal colectomy & $5(2)$ \\
Hartmanns & $7(3)$ \\
Reversal Hartmanns & $8(3)$ \\
Small bowel resection & $24(9)$ \\
Anterior resection & $77(28)$ \\
Proctocolectomy & $8(3)$ \\
Other procedures & $23(8)$ \\
Total & $280(100)$ \\
\hline
\end{tabular}

A significant difference was seen between mean resting pain scores at 24 hours $(1.34)$ and 48 hours $(2.10)(\mathrm{P}<0.01)$ for all cases. These differences were significant in the anterior resection and other-procedures subgroups $(\mathrm{P} \leq 0.01$ and $\mathrm{P}=0.04$, respectively). Table 3 shows the full subgroup analysis breaking down the pain scores by procedure. A significant difference was also seen between average dynamic pain scores at 24 hours (3.09) and 48 hours (4.17) $(\mathrm{P}<0.01)$ for all cases. This difference was again significant in the anterior resection subgroup. Additionally, the difference in dynamic pain scores at 24 and 48 hours was significant in the right hemicolectomy subgroup. Table 4 shows the full subgroup analysis. Table 5 compares pain scores between the laparoscopic and the open surgery groups. There is a trend towards better resting and dynamic pain scores in the laparoscopic group at both time points. Statistical significance is seen at 48 hours in resting pain scores and at 24 hours in dynamic pain scores.

Data were recorded for $97 \%$ of patients at 24 hours and at 48 hours. Of the patients, $81 \%$ required simple analgesia (IV para-

Table 2. Other procedures

\begin{tabular}{lc}
\hline Procedure & No. of cases (\%) \\
\hline Laparotomy + abdominoplasty & $1(4)$ \\
Laparotomy + adhesiolysis & $13(57)$ \\
Laparotomy + colovesical fistula repair & $1(4)$ \\
Laparotomy + incisional hernia repair & $5(22)$ \\
Laparotomy + mesenteric cyst excision & $1(4)$ \\
Laparotomy + splenectomy & $1(4)$ \\
Laparotomy + stoma refashioning & $1(4)$ \\
Total & $23(100)$ \\
\hline
\end{tabular}

Table 3. Mean (standard deviation) resting pain scores at 24 and 48 hours

\begin{tabular}{lccc}
\hline \multirow{2}{*}{ Procedure group } & \multicolumn{2}{c}{ Resting pain score } & \multirow{2}{*}{ t-test } \\
\cline { 2 - 3 } & 24 Hours & 48 Hours & \\
\hline Right hemicolectomy & $1.41(2.28)$ & $2.06(2.56)$ & 0.08 \\
Left hemicolectomy & $1.10(1.99)$ & $1.66(2.38)$ & 0.23 \\
Total colectomy & $0(0)$ & $2.75(2.22)$ & 0.09 \\
Subtotal colectomy & $1.75(2.87)$ & $1.60(3.58)$ & 0.72 \\
Hartmanns & $3.17(4.12)$ & $3.67(1.97)$ & 1.00 \\
Reversal Hartmanns & $1.63(1.85)$ & $2.63(2.92)$ & 0.31 \\
Small bowel resection & $1.91(2.50)$ & $2.30(2.67)$ & 0.68 \\
Anterior resection & $1.27(2.06)$ & $2.24(2.39)$ & $<0.01^{\mathrm{a}}$ \\
Proctocolectomy & $0.71(1.89)$ & $1.00(1.73)$ & 0.80 \\
Other procedures & $0.95(1.72)$ & $2.16(2.61)$ & $0.04^{\mathrm{a}}$ \\
All groups & $1.34(2.19)$ & $2.10(2.48)$ & $<0.01$ \\
\hline
\end{tabular}

Values are presented as mean (standard deviation).

aSignificant at $\mathrm{P}<0.05$ using the paired two-tailed t-test. 
Table 4. Mean (standard deviation) dynamic pain scores at 24 and 48 hours

\begin{tabular}{lccc}
\hline \multirow{2}{*}{ Procedure group } & \multicolumn{2}{c}{ Dynamic pain score } & \multirow{2}{*}{ t-test } \\
\cline { 2 - 3 } & 24 Hours & 48 Hours & \\
\hline Right hemicolectomy & $3.22(3.30)$ & $4.44(2.85)$ & $<0.01^{\mathrm{a}}$ \\
Left hemicolectomy & $2.61(2.68)$ & $3.59(2.92)$ & 0.07 \\
Total colectomy & $0(0)$ & $3.50(2.38)$ & 0.06 \\
Subtotal colectomy & $2.50(3.79)$ & $3.60(4.93)$ & 0.72 \\
Hartmanns & $3.83(3.92)$ & $7.14(2.48)$ & 0.13 \\
Reversal Hartmanns & $5.38(3.50)$ & $5.50(3.07)$ & 0.91 \\
Small bowel resection & $4.43(3.42)$ & $4.30(3.71)$ & 0.89 \\
Anterior resection & $2.68(2.98)$ & $4.07(3.07)$ & $<0.01^{\mathrm{a}}$ \\
Proctocolectomy & $3.38(3.07)$ & $3.88(3.56)$ & 0.64 \\
Other procedures & $3.00(2.91)$ & $3.26(3.38)$ & 0.61 \\
All groups & $3.09(3.14)$ & $4.17(3.12)$ & $<0.01$ \\
\hline
\end{tabular}

Values are presented as mean (standard deviation).

aSignificant at $P<0.05$ using the paired two-tailed t-test.

Table 5. Comparison of pain scores between the laparoscopic and the open groups

\begin{tabular}{lccc}
\hline \multirow{2}{*}{ Pain score } & \multicolumn{2}{c}{ Procedure group } & \multirow{2}{*}{ t-test } \\
\cline { 2 - 3 } & \multicolumn{1}{c}{ Open } & Laparoscopic & \\
\hline Resting pain score & & & \\
24 Hours & $1.57(1.81)$ & $1.35(1.13)$ & 0.08 \\
$\quad$ 48 Hours & $2.41(2.51)$ & $2.12(1.45)$ & $0.05^{\mathrm{a}}$ \\
Dynamic pain score & & & \\
24 Hours & $3.62(1.92)$ & $2.84(2.38)$ & $0.045^{\mathrm{a}}$ \\
48 Hours & $4.5(3.77)$ & $4.25(4.93)$ & 0.07 \\
\hline
\end{tabular}

Values are presented as mean (standard deviation).

a Significant at $\mathrm{P}<0.05$ using the paired two-tailed t-test. cetamol +/- NSAIDS) alone at 24 hours. Ten percent required oramorph, and a further $9 \%$ required patient-controlled analgesia (PCA). At 48 hours, $62 \%$ of patients received adequate pain control with simple analgesics alone while $26 \%$ required additional oramorph and a further $12 \%$ required PCA (Table 6).

Data on mobilization at 24 hours was recorded for 252 of the total 280 patients (90\%). Of these patients, $77 \%$ were mobilized at 24 hours (193 patients). Table 6 shows the subgroup analysis. Data on mobilization at 48 hours was recorded for 244 patients of the total 280 patients (87\%). Of these patients, $90 \%$ were mobilized at 48 hours (219 patients). Table 7 shows the subgroup analysis.

The median length of stay for all patients, including patients undergoing emergency surgery, was 6 days, with an IQR of 4 days. Table 8 shows the subgroup analysis, and further breaks down the length of stay by the procedure performed. Side effects were also

Table 7. Mobilization at 24 and 48 hours

\begin{tabular}{lccccc}
\hline \multirow{2}{*}{ Procedure group } & \multicolumn{2}{c}{ Mobilization at 24 hours } & & \multicolumn{2}{c}{ Mobilization at 48 hours } \\
\cline { 2 - 3 } \cline { 6 - 6 } & $\begin{array}{c}\text { Data } \\
\text { recorded }\end{array}$ & $\begin{array}{c}\text { Patients } \\
\text { mobilizing }\end{array}$ & & $\begin{array}{c}\text { Data } \\
\text { recorded }\end{array}$ & $\begin{array}{c}\text { Patients } \\
\text { mobilizing }\end{array}$ \\
\hline Right hemicolectomy & 78 & $64(82)$ & & 72 & $65(90)$ \\
Left hemicolectomy & 37 & $33(89)$ & & 37 & $35(95)$ \\
Total colectomy & 4 & $3(75)$ & & 4 & $3(75)$ \\
Subtotal colectomy & 5 & $3(60)$ & & 4 & $3(75)$ \\
Hartmanns & 6 & $3(50)$ & 6 & $5(83)$ \\
Reversal Hartmanns & 8 & $4(50)$ & 8 & $8(100)$ \\
Small bowel resection & 19 & $15(79)$ & & 18 & $15(83)$ \\
Anterior resection & 67 & $49(73)$ & 69 & $63(91)$ \\
Proctocolectomy & 8 & $5(63)$ & 8 & $7(88)$ \\
Other procedures & 20 & $14(70)$ & & 18 & $15(83)$ \\
All procedures & 252 & $193(77)$ & & 244 & $219(90)$ \\
\hline
\end{tabular}

Table 6. Additional analgesia requirements at 24 and 48 hours

\begin{tabular}{|c|c|c|c|c|c|c|c|c|}
\hline \multirow{2}{*}{ Procedure group } & \multicolumn{4}{|c|}{ Additional analgesia requirements at 24 hours } & \multicolumn{4}{|c|}{ Additional analgesia requirements at 48 hours } \\
\hline & Data recorded & Simple analgesia alone & PCA & Oramorph & Data recorded & Simple analgesia alone & PCA & Oramorph \\
\hline Right hemicolectomy & $80(98)$ & $66(83)$ & $4(5)$ & $10(13)$ & $79(96)$ & $53(67)$ & $6(8)$ & $20(25)$ \\
\hline Left hemicolectomy & $41(97)$ & $34(83)$ & $3(7)$ & $4(10)$ & $40(95)$ & $28(70)$ & $4(10)$ & $9(23)$ \\
\hline Total colectomy & $4(100)$ & $4(100)$ & $0(0)$ & $0(0)$ & $4(100)$ & $4(100)$ & $0(0)$ & $0(0)$ \\
\hline Subtotal colectomy & $5(100)$ & $3(60)$ & $1(20)$ & $1(20)$ & $5(100)$ & $1(20)$ & $1(20)$ & $3(60)$ \\
\hline Hartmanns & $7(100)$ & $4(57)$ & $2(29)$ & $1(14)$ & $7(100)$ & $3(43)$ & $3(43)$ & $1(14)$ \\
\hline Reversal Hartmanns & $8(100)$ & $7(88)$ & $0(0)$ & $1(13)$ & $8(100)$ & $5(62.5)$ & $0(0)$ & $3(38)$ \\
\hline Small bowel resection & $23(96)$ & $17(74)$ & $3(13)$ & $3(13)$ & $22(92)$ & $16(73)$ & $3(14)$ & $3(14)$ \\
\hline Anterior resection & $76(99)$ & $53(70)$ & $8(11)$ & $15(20)$ & 77 (100) & $44(57)$ & $9(12)$ & $24(31)$ \\
\hline Proctocolectomy & $8(100)$ & $5(63)$ & $2(25)$ & $1(13)$ & $8(100)$ & $5(62.5)$ & $2(25)$ & $1(13)$ \\
\hline Other procedures & $20(87)$ & $14(70)$ & $2(10)$ & $4(20)$ & $22(92)$ & $11(50)$ & $4(19)$ & 7 (33) \\
\hline Total & $272(97)$ & $221(81)$ & $25(9)$ & $26(10)$ & $272(97)$ & 169 (62) & $32(12)$ & $71(26)$ \\
\hline
\end{tabular}

Values are presented as number (\%). 
Table 8. Length of stay by procedure group

\begin{tabular}{lc}
\hline Procedure group & Length of stay in days \\
\hline Right hemicolectomy & $5.00(4.00)$ \\
Left hemicolectomy & $5.00(2.75)$ \\
Total colectomy & $6.00(8.75)$ \\
Subtotal colectomy & $13.00(8.00)$ \\
Hartmanns & $11.00(6.00)$ \\
Reversal Hartmanns & $5.50(2.50)$ \\
Small bowel resection & $6.00(7.50)$ \\
Anterior resection & $5.00(3.00)$ \\
Proctocolectomy & $7.00(1.50)$ \\
Other procedures & $7.00(5.00)$ \\
All procedures & $6.00(4.00)$ \\
\hline
\end{tabular}

Values are presented as median (interquartile range).

recorded during the first 48 hours postoperatively. Common side effects were transient hypotension, prolonged sedation, pruritus and nausea. Table 9 summarizes the side-effect profile.

\section{DISCUSSION}

The enhanced recovery program (ERP) in colorectal surgery is well established and evidence based [9]. The key factors influencing recovery in the postoperative phase and thereby affecting hospital stay are recognized to be the need for parenteral analgesia, fluid balance/monitoring (i.e., intravenous fluids and urinary catheterization), and mobility $[9,10]$.

Optimal pain relief and early mobilization in particular have been associated with improvements in physical performance and pulmonary function and with a marked reduction in length of hospital stay [11-14].

Several controlled trials and a Cochrane review have established that optimal analgesia allowing early mobilization is best achieved by using continuous epidural local anesthetic or local anestheticopioid techniques $[14,15]$. The optimal duration for continuous epidural anesthesia has not been well investigated in randomized trials, but large case series suggest that a minimum of two days is necessary in major colorectal surgery [15]. This often means a dependence an epidural catheterization, infusion pumps, urinary catheterization, and intravenous fluids. In our series, no epidural catheters and no epidural infusion pumps were used for any of the patients.

In our series $60 \%$ of the procedures were open, and this is typical of most hospitals in the UK. Whilst a single spinal injection has been shown to be effective and adequate in laparoscopic surgery, epidural infusion for 48 hours has been shown to be the gold standard in open surgery [14]. Our series also shows effective resting and dynamic analgesia in this open group. The greatest advantages of DepoDur ${ }^{\mathbb{B}}$ in terms of early mobilization are likely to be
Table 9. Side effects recorded $(\mathrm{n}=277)$

\begin{tabular}{lc}
\hline Side effect & No. of cases (\%) \\
\hline Transient hypotension & $75(27)$ \\
Urinary retention & $11(4)$ \\
Respiratory compromise & $52(19)$ \\
Sedation & $11(4)$ \\
Pruritus & $77(28)$ \\
Nausea & $72(26)$ \\
Motor block & $5(2)$ \\
Confusion & $26(9)$ \\
\hline
\end{tabular}

seen in the open surgery group.

When comparing all cases, significant differences in resting pain and dynamic pain at 24 and 48 hours were seen. This is to be expected as the DepoDur ${ }^{\circledR}$ injection is not as effective after 48 hours. We should note, however, that the overall pain scores were low and below 5 (out of a maximum of 10) - suggesting good pain control even at 48 hours. Also, the resting and dynamic pain scores seen at 24 and 48 hours for laparoscopic surgery were lower than those seen for open surgery. This is to be expected as the smaller number of incisions associated with laparoscopic surgery are recognized to result in less postoperative pain.

Intravenous opiates have greater cardiac and respiratory complications and may prolong the duration of gastrointestinal ileus when compared to epidural opiates $[16,17]$, and this may further delay recovery. Encouragingly, in our cohort, approximately 30\% of all patients did not require any additional opiate analgesia, and only $12 \%$ of the patients required a PCA at 48 hours.

Immobility increases insulin resistance and muscle loss and decreases muscle strength, pulmonary function and tissue oxygenation [10]. Almost $80 \%$ of the patients in our cohort were mobilized at 24 hours, and $93 \%$ were mobilized at 48 hours. The lack of epidural catheters and infusion pumps facilitated earlier mobilization and faster recovery.

The highest pain scores, the greatest analgesic requirements and the lowest mobilization rates were seen in the Hartman's operation group. This may be because these operations are often done as emergencies, and the patients are generally in worse condition than the other patients in the cohort. However, these factors were not specifically investigated, and the overall number of Hartman's procedures was small, so no definitive conclusions could be drawn.

A recent randomized control trial comparing epidural to spinal anesthesia and PCA alone in laparoscopic colorectal resections has shown that epidural anesthesia was significantly worse in terms of length of stay, time to return of bowel function. and duration of nausea [15]. Our unique series included open colorectal surgery and identified further potential advantages over PCA and spinal anesthesia, and this may be an area for future studies.

The lengths of stay for our cohort were similar to those for a published series [9]. The results would, therefore, suggest that De- 
poDur $^{\circledR}$ is not a key element in reducing the length of hospital stay. Similar results have been reported in the literature on epidurals and PCA $[15,18]$. We have shown that DepoDur ${ }^{\mathbb{R}}$ is an effective analgesic that may promote early mobilization. Early mobilization has been shown to prevent complications.

Khuri et al. [19] reported that the occurrence of any complications 30 day postoperatively had a detrimental effect on overall survival after major surgery. A reduction in complications may, therefore, result in increased long-term survival. The side-effect profile is shown in Table 8, and this is in keeping with published literature [6]. Transient hypotension, respiratory compromise, pruritus, and nausea were the most common side effects. Whilst these are established side effects of opiates, one must bear in mind that at least some will be secondary to the surgery and/or anesthetic agent used.

Trials involving the use of extended-release epidural morphine are lacking. In one small randomized control trial, single-dose extended-release morphine was compared with standard epidural infusion, and requirements for additional analgesia were found to be reduced. No data were provided on mobilization [5]. Well-designed, appropriately-powered, randomized, controlled trials are needed. Our large case series is not a trial, and we have not made direct comparisons with traditional epidural infusions or other forms of postoperative analgesia. It does, however, serve to highlight the advantages of extended-release epidural morphine (DepoDur $\left.{ }^{\circledR}\right)$ in the context of colorectal surgery. In particular, we have shown encouraging results in pain management and early mobilization. Such advantages may improve overall survival and serve to enhance the ERP. This prospective study also provides encouraging data that justifies a randomized, controlled trail, and preliminary data from this study can be used to design a strong, appropriately-powered, randomized, control trial.

\section{CONFLICT OF INTEREST}

No potential conflict of interest relevant to this article was reported.

\section{REFERENCES}

1. Depodur [package insert]. Bedminster, NJ: EKR Therapeutics Inc.; 2007.

2. Martin G, Hartmannsgruber M, Riley E, Manvelian G. Singledose extended-release epidural morphine for pain after hip arthroplasty. J Opioid Manag 2006;2:209-18.

3. Viscusi ER, Martin G, Hartrick CT, Singla N, Manvelian G; EREM Study Group. Forty-eight hours of postoperative pain relief after total hip arthroplasty with a novel, extended-release epidural morphine formulation. Anesthesiology 2005;102:1014-22.

4. Carvalho B, Riley E, Cohen SE, Gambling D, Palmer C, Huffnagle $\mathrm{HJ}$, et al. Single-dose, sustained-release epidural morphine in the management of postoperative pain after elective cesarean deliv- ery: results of a multicenter randomized controlled study. Anesth Analg 2005;100:1150-8.

5. Gambling D, Hughes T, Martin G, Horton W, Manvelian G. A comparison of Depodur, a novel, single-dose extended-release epidural morphine, with standard epidural morphine for pain relief after lower abdominal surgery. Anesth Analg 2005;100:106574.

6. Viscusi ER. Patient-controlled drug delivery for acute postoperative pain management: a review of current and emerging technologies. Reg Anesth Pain Med 2008;33:146-58.

7. Viscusi ER. Emerging techniques in the management of acute pain: epidural analgesia. Anesth Analg 2005;101(5 Suppl):S23-9.

8. Hartrick CT, Martin G, Kantor G, Koncelik J, Manvelian G. Evaluation of a single-dose, extended-release epidural morphine formulation for pain after knee arthroplasty. J Bone Joint Surg Am 2006;88:273-81.

9. Varadhan KK, Neal KR, Dejong CH, Fearon KC, Ljungqvist O, Lobo DN. The enhanced recovery after surgery (ERAS) pathway for patients undergoing major elective open colorectal surgery: a meta-analysis of randomized controlled trials. Clin Nutr 2010;29: 434-40.

10. Fearon KC, Ljungqvist O, Von Meyenfeldt M, Revhaug A, Dejong $\mathrm{CH}$, Lassen $\mathrm{K}$, et al. Enhanced recovery after surgery: a consensus review of clinical care for patients undergoing colonic resection. Clin Nutr 2005;24:466-77.

11. Basse L, Raskov HH, Jakobsen DH, Sonne E, Billesbolle P, Hendel HW, et al. Accelerated postoperative recovery programme after colonic resection improves physical performance, pulmonary function and body composition. Br J Surg 2002;89:446-53.

12. Basse L, Hjort Jakobsen D, Billesbolle P, Werner M, Kehlet H. A clinical pathway to accelerate recovery after colonic resection. Ann Surg 2000;232:51-7.

13. Basse L, Thorbol JE, Lossl K, Kehlet H. Colonic surgery with accelerated rehabilitation or conventional care. Dis Colon Rectum 2004;47:271-7.

14. Jorgensen H, Wetterslev J, Moiniche S, Dahl JB. Epidural local anaesthetics versus opioid-based analgesic regimens on postoperative gastrointestinal paralysis, PONV and pain after abdominal surgery. Cochrane Database Syst Rev 2000;(4):CD001893.

15. Levy BF, Scott MJ, Fawcett W, Fry C, Rockall TA. Randomized clinical trial of epidural, spinal or patient-controlled analgesia for patients undergoing laparoscopic colorectal surgery. Br J Surg 2011;98:1068-78.

16. Liu S, Carpenter RL, Neal JM. Epidural anesthesia and analgesia: their role in postoperative outcome. Anesthesiology 1995;82:1474506 .

17. Kehlet H, Wilmore DW. Multimodal strategies to improve surgical outcome. Am J Surg 2002;183:630-41.

18. Turunen P, Carpelan-Holmstrom M, Kairaluoma P, Wikstrom H, Kruuna O, Pere P, et al. Epidural analgesia diminished pain but did not otherwise improve enhanced recovery after laparoscopic sigmoidectomy: a prospective randomized study. Surg Endosc 
2009;23:31-7.

19. Khuri SF, Henderson WG, DePalma RG, Mosca C, Healey NA, Kumbhani DJ, et al. Determinants of long-term survival after ma- jor surgery and the adverse effects of postoperative complications. Ann Surg. 2005; 242:326-43. 